\title{
PERBEDAAN TRANSMISI TEKANAN PADA BASIS GIGI TIRUAN RESIN AKRILIK POLIMERISASI PANAS DAN NILON TERMOPLASTIK
}

\author{
Elis Crystal'), Hubban Nasution ${ }^{2)}$ \\ Fakultas Kedokteran Gigi Universitas Sumatera Utara \\ Departemen Prostodonsia Universitas Sumatera Utara
}

\begin{abstract}
Abstrak
The purpose of this study was to evaluate The Difference in Pressure Transmission between Polymethyl-Methacrylate (PMMA) and Thermoplastic Nylon Denture Based. Material and methods: Mandibular first molar acrylic denture teeth (Bioeco) embedded on $15 \times 15 \times 3 \mathrm{~mm}^{3}$ thermoplastic nylon (Biotone) and poly methyl methacrylate denture bases were evaluated $(n=9)$. A $100 \mathrm{~N}$ force applied on the specimen using universal testing machine and the pressure transmitted under the specimen observed using pressure transducer. Results: The results showed that polymethyl methacrylate has the highest pressure transmission compared to thermoplastic nylon. This study can help dentists to determine the design of dentures, especially in the selection of denture base materials.
\end{abstract}

Kata Kunci: Anasir Gigi Tiruan, Basis Gigi Tiruan, Nilon Termoplastik, Resin Akrilik Polimerisasi Panas

\section{PENDAHULUAN}

Beberapa penelitian telah mengevaluasi beberapa bahan pada basis gigi tiruan. Sejak ditemukan oleh Walter Bauer (1936), bahan basis gigi tiruan resin akrilik secara bertahap mengambil tempat basis logam tradisional dan menjadi bahan yang paling banyak digunakan sebagai bahan basis gigi tiruan (Vivek 2015, Vivek dan Soni 2015). Resin akrilik yang sering digunakan adalah resin akrilik polimerisasi panas (RAPP). Resin akrilik polimerisasi panas ini tersedia dalam bentuk bubuk dan cairan yang dicampur serta membutuhkan energi panas untuk menjadi kaku dan padat. Bahan tersebut mudah dimanipulasi dan mudah direparasi bila terjadi fraktur, memiliki warna yang stabil, tidak toksik, tidak larut dalam cairan mulut dan harganya ekonomis. Adapun kekurangan resin akrilik polimerisasi sebagai basis gigi tiruan yaitu flexibilitas kurang baik, dapat menyebabkan alergi pada pasien yang alergi terhadap resin (Sundari dkk. 2016,
Cunningham 1993, Kohli dan Bhatia 2013).

Bahan termoplastik resin adalah bahan yang tidak mengalami perubahan kimia dalam proses pembentukannya, sehingga dapat dilunakkan dan dibentuk berulang kali dengan suhu dan tekanan yang tinggi tanpa terjadi perubahan kimia, contoh resin termoplastik beserta nama produk antara lain polikarbonat (Reigning $S$ dan JET Carbo Resin), polyester (EstheShot), akrilik resin (Acry Tone) dan nilon termoplastik (BioPlast, Biotone, Valplast, Lucitone, Lucitone FRS, Flex Star V, TCS, dan Ultimate) (Kohli dan Bhatia 2013, Fueki dkk. 2014).

Nilon termoplastik dikenal sebagai poliamida yang pada awalnya merupakan hasil penelitian dari W.H Carothers dan $D u$ Pont Chemical Co. of America pada tahun 1928-1938. Poliamida merupakan turunan polimer yang dihasilkan oleh reaksi kondensasi monomer diamin $\mathrm{NH}_{2}-\left(\mathrm{CH}_{2}\right)_{6}$ $\mathrm{NH}_{2}$ dan dibasic acid $\mathrm{CO}_{2} \mathrm{H}-\left(\mathrm{CH}_{2}\right)_{4^{-}}$ $\mathrm{COOH}$. Poliamida merupakan polimer 
kristalin yang memiliki nilai estetis dan memiliki kekurangan yaitu tingkat penyerapan air yang tinggi (Vivek 2015, Kohli dan Bhatia 2013). Poliamida memiliki beberapa jenis yang telah dimodifikasi seperti poliamida 12 dan poliamida mikrokristalin, kedua jenis tersebut memiliki nilai estetis yang baik dan flexibilitas (Sari dkk. 2017)

Menurut Kordatzis dkk., meskipun peningkatan resorpsi pada tulang terlihat pada orang yang menggunakan gigi tiruan dengan adanya tekanan yang diberikan pada gigi tiruan, disarankan jumlah tekanan dalam batas toleransi fisiologis dan diterapkan secara normal agar dapat merangsang aposisi tulang. Ortman menganggap resorpsi tulang adalah sebuah hal yang normal dengan diseimbangkan oleh adanya aposisi tulang. Jika tekanan pada gigi tiruan dapat mengubah suplai darah pada tulang atau menyebabkan inflamasi pada mukoperiosteum maka resorpsi tulang dapat terjadi. Matsuo dkk., mengatakan bahwa tekanan 27 hingga 68 $\mathrm{g} / \mathrm{cm}^{2}$ menyebabkan fibroblast merangsang peningkatan kalsium intraseluler yang dapat membantu remodeling tulang alveolar. Berg dkk., juga menyatakan bahwa tekanan yang melebihi $1,3 \mathrm{kPa}$ tidak boleh didistribusikan ke jaringan pendukung gigi tiruan. Serta lebih disarankan untuk merancang gigi tiruan dengan tujuan untuk melindungi struktur rongga mulut yang tersisa dan menurunkan tekanan ke sisa alveolar (Arksornnukit dkk. 2011, Phunthikaphadr dkk. 2009).

Salah satu penyebab resorpsinya tulang alveolar pada pengguna gigi tiruan adalah dari sifat mekanis seperti kekerasan permukaan dan modulus elastisitas. Pada penelitian sebelumnya Nasution dkk., (2018) didapatkan adanya tekanan yang muncul di dasar permukaan basis atau disebut sebagai transmisi tekanan. Adanya faktor-faktor yang memengaruhi terhadap transmisi tekanan pada dasar basis adalah kekerasan permukaan dan modulus elastisitas (Arksornnukit dkk. 2011).
Modulus elastisitas adalah ukuran kekakuan relatif suatu bahan sampai batas elastisnya dan menggambarkan kemampuan suatu bahan untuk menerima tekanan tanpa mengalami patah maupun kerusakan yang permanen. Persyaratan modulus elastisitas suatu basis gigi tiruan sesuai standar ISO 1567 adalah sedikitnya $2000 \mathrm{MPa}$. Nilai modulus elastisitas nilon termoplastik lebih rendah dari standar yakni sebesar $826 \mathrm{MPa}$ (Sundari dkk. 2016, Tenripada dkk. 2014). Kekerasan permukaan merupakan resistensi suatu bahan terhadap deformasi plastis, yang biasanya diukur dibawah beban indentasi. Nilai kekerasan telah digunakan sebagai ukuran sifat mekanis suatu bahan dan untuk memprediksi ketahanan aus suatu bahan (Hamanaka dkk. 2016).

Selain dari kekerasan permukaan dan modulus elastisitas yang dapat menyebabkan resorpsinya tulang alveolar, bentuk dari anasir gigi juga ternyata dapat memengaruhi hal tersebut. Penelitian yang dilakukan oleh Arksornnukit dkk., (2011) menyatakan bahwa adanya variasi transmisi tekanan yang berbeda dengan menggunakan bentuk anasir gigi tiruan yang berbeda seperti anatomis, non anatomis dan semi anatomis terhadap material basis gigi tiruan yang berbeda pula (Arksornnukit dkk. 2011). Hal tersebut diduga sebagai salah satu penyebab terjadinya resorpsi tulang alveolar walaupun belum adanya penelitian yang mengkorelasi antara transmisi tekanan dari suatu material terhadap resorpsinya tulang alveolar (Nasution dkk. 2018).

\section{METODE}

Rancangan penelitian dalam
penelitian ini adalah penelitian
eksperimental laboratoris. Sampel pada
penelitian ini adalah anasir gigi tiruan
akrilik molar satu rahang bawah, basis gigi
tiruan yang terdiri atas bahan resin akrilik
polimerisasi panas dan bahan nilon


termoplastik dengan merek Biotone (Denken-Highdental Co., Ltd., Kyoto,

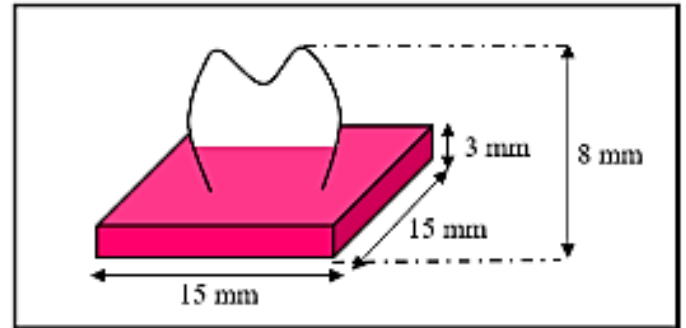

Japan). Basis yang digunakan sebagai tempat menanam anasir gigi tiruan berbentuk persegi dengan panjang $15 \mathrm{~mm}$, lebar $15 \mathrm{~mm}$ dan tinggi $3 \mathrm{~mm}$. Tinggi total dari dasar basis hingga anasir gigi tiruan adalah 8mm (Gambar 1).

Gambar 1. Bentuk dan ukuran sampel

Pengukuran dilakukan dengan menggunakan alat Universal Testing Machine (EHF-EB100KN-20L, Shimadzu Co., Japan) dan Pressure Transducer (Teknik Mesin USU). Pengujian transmisi tekanan ini dilakukan untuk mengetahui besar transmisi tekanan pada dasar basis gigi tiruan dengan menggunakan resin akrilik polimerisasi panas dan bahan nilon termoplastik merek Biotone.

Prosedur yang akan dilakukan adalah tempatkan sampel diatas Pressure Transducer yang telah ditempatkan pada Universal Testing Machine. Anasir gigi tiruan antagonis diletakkan pada alat pencekam (indenter) dibagian atas yang terdapat pada Universal Testing Machine dengan double tape. Beban diberikan pada bagian oklusal dengan menggunakan anasir gigi tiruan antagonis (kontak oklusal) terhadap sampel basis gigi tiruan menggunakan kecepatan sebesar 0,5 mm per menit dengan beban tekan hingga mencapai $100 \mathrm{~N}$ dan langsung diberhentikan. Nilai transmisi tekanan pada dasar basis gigi tiruan dibaca melalui Pressure Transducer (Gambar 2).

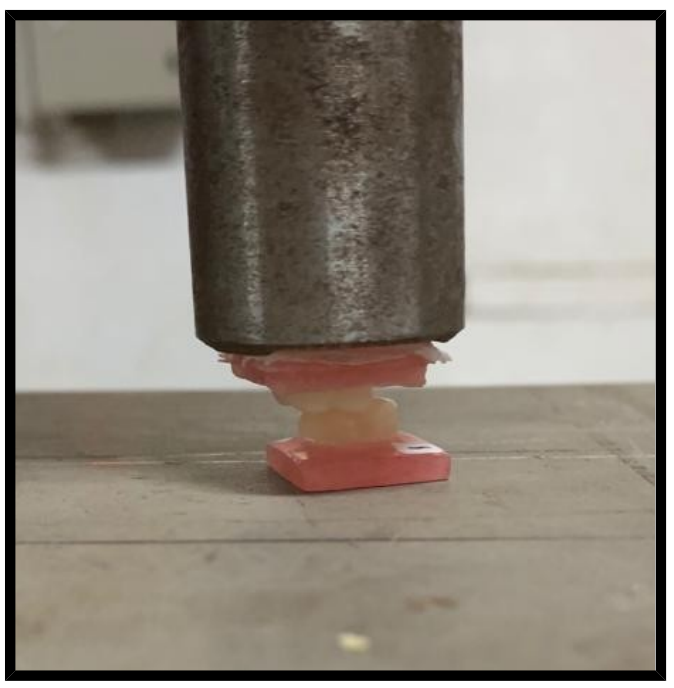

Gambar 2. Pengukuran transmisi tekanan

\section{HASIL DAN PEMBAHASAN}

Dari hasil analisis univarian nilai rerata transmisi tekanan pada dasar basis gigi tiruan kelompok RAPP adalah $(90,171$ $\pm 3,705 \mathrm{~N})$. Nilai rerata transmisi tekanan pada dasar basis gigi tiruan kelompok Biotone adalah $(69,122 \pm 2,213 \mathrm{~N})$ (Tabel 1).

Tabel 1. Nilai transmisi tekanan pada dasar basis gigi tiruan resin akrilik polimerisasi panas dan nilon termoplastik Biotone

\begin{tabular}{|c|c|c|}
\hline \multirow{2}{*}{$\begin{array}{c}\text { No. } \\
\text { Sampel }\end{array}$} & \multicolumn{2}{|c|}{ Transmisi Tekanan (N) } \\
\cline { 2 - 3 } & RAPP & Biotone \\
\hline 1 & 94,11 & 70,89 \\
\hline 2 & 89,22 & $72,11^{* *}$ \\
\hline 3 & 90,44 & 67,22 \\
\hline 4 & 92,89 & $66^{*}$ \\
\hline 5 & 89,22 & 68,44 \\
\hline 6 & 86,78 & 68,44 \\
\hline 7 & 86,78 & 69,67 \\
\hline 8 & $96,55^{* *}$ & $72,11^{* *}$ \\
\hline 9 & $85,55^{*}$ & 67,22 \\
\hline $\bar{x} \pm$ SD & $90,171 \pm$ & $69,122 \pm$ \\
& 3,705 & 2,213 \\
\hline \multicolumn{2}{|c|}{ Dari } & hasil uji $t$-test diperoleh \\
\hline
\end{tabular}

signifikansi $p=0,001 \quad(p<0,05)$ hal ini menunjukkan adanya perbedaan transmisi tekanan yang signifikan antara basis gigi 
tiruan resin akrilik polimerisasi panas dan nilon termoplastik Biotone (Grafik 1).

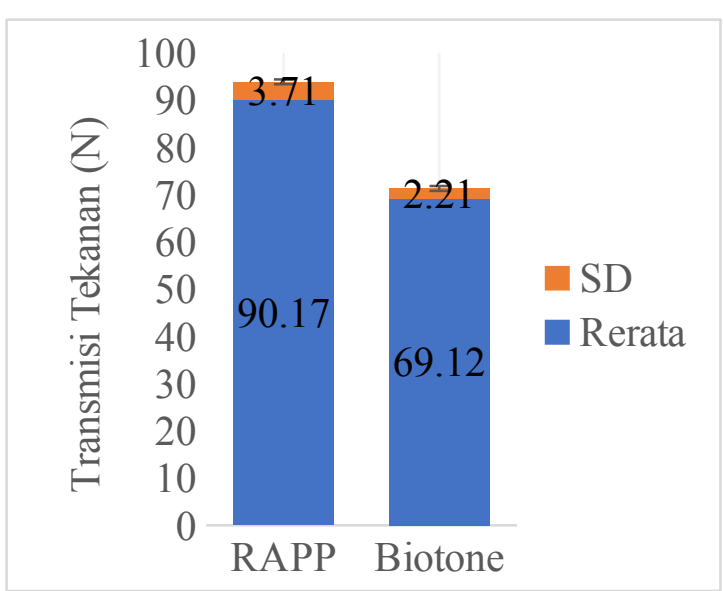

Grafik 1. Rata-rata nilai transmisi tekanan (N) kelompok RAPP dan Biotone; garis vertikal menunjukkan standar deviasi; huruf yang berbeda menunjukkan adanya perbedaan yang signifikan

Perbedaan transmisi tekanan dapat terjadi karena adanya faktor yang memengaruhi nilai transmisi tekanan pada dasar basis yaitu pemilihan bahan basis gigi tiruan, pemilihan anasir gigi tiruan dan sistem retensi. Setiap basis gigi tiruan memiliki polimer rantai ikatan masingmasing. Poliamida merupakan polimer dengan bentuk rantai tunggal sehingga lebih mudah untuk mengalami proses kristalisasi dibandingkan polimer yang membentuk rantai cross-linking dan bercabang. Tingkat kristalisasi suatu polimer dapat memengaruhi sifat-sifat suatu bahan, seperti modulus elastisitas, kekuatan, kekakuan dan sebagainya (Anusavice 2012, Callister dan Rethwisch 2010). Anasir gigi tiruan dengan modulus elastisitas yang lebih rendah dapat melenturkan dan menyerap gaya dan mengurangi distribusi tekanan pada dasar basis. Pada penelitian sebelumnya didapatkan bahwa pemilihan jenis anasir gigi tiruan dapat memengaruhi nilai transmisi tekanan dimana nilai transmisi tekanan pada anasir gigi tiruan akrilik lebih kecil $(0,76 \mathrm{MPa})$ dibanding anasir gigi tiruan porselen $(1,01 \mathrm{MPa})$. Pemilihan bentuk anasir juga dapat memengaruhi nilai transmisi tekanan, semakin kecil angulasi suatu anasir gigi tiruan maka semakin kecil nilai transmisi tekanan (Hamanaka dkk. 2016). Sistem retensi bertujuan untuk meningkatkan ikatan antara bahan dengan anasir gigi tiruan. Sistem retensi terbagi atas dua yaitu sistem retensi secara kemis dan sistem retensi secara mekanis (menggunakan pin atau diatoric holes) (Saavedra dkk. 2007). Pada penelitian ini sistem retensi dan anasir gigi tiruan yang digunakan pada seluruh sampel sama yaitu dengan menggunakan T-Shaped diatoric holes dan anasir gigi tiruan akrilik molar 1 kanan rahang bawah. Maka pada penelitian ini sistem retensi dan jenis anasir gigi tiruan tidak menjadi variabel yang memengaruhi nilai transmisi tekanan.

Perbedaan transmisi tekanan dapat berbeda karena setiap bahan memiliki nilai modulus elastisitas dan kekerasan yang berbeda. Kedua sifat mekanis tersebut dapat memengaruhi nilai transmisi tekanan pada dasar basis gigi tiruan RAPP dan Biotone. Modulus elastisitas dipengaruhi oleh polimer rantai ikatan yang berbeda dan adanya gaya interatomik dan intermolekular pada suatu bahan. Nilai modulus elastisitas yang semakin besar dipengaruhi oleh adanya ikatan antar atom yang semakin kuat pada suatu bahan. Nilai modulus elastisitas yang semakin tinggi menandakan semakin kaku suatu material, semakin besar gaya yang dibutuhkan untuk menahan atau menerima beban yang diberikan. Basis gigi tiruan RAPP merupakan polimer amorphous yang membentuk ikatan cross-linking dan memiliki nilai modulus elastisitas lebih besar dibandingkan Biotone yang merupakan golongan poliamida mikrokristalin (Kohli dan Bhatia 2013, Tenripada dkk. 2014). Biotone merupakan golongan poliamida mikrokristalin dengan karakteristik lebih keras dibandingkan dengan golongan poliamida lainnya. Poliamida tersebut merupakan poliamida 
generasi baru yang diciptakan untuk menutupi kekurangan dari poliamida lainnya.

Berdasarkan hasil penelitian ini, transmisi tekanan yang tertinggi terjadi pada kelompok RAPP dan transmisi tekanan yang terendah terjadi pada kelompok Biotone. Hal ini sejalan dengan hasil penelitian terdahulu tentang transmisi tekanan. Menurut penelitian Nasution dkk., (2018) didapatkan bahwa basis gigi tiruan kelompok RAPP memiliki nilai transmisi tekanan yang paling tinggi dibandingkan dengan kelompok nilon termoplastik lainnya. Nilai transmisi tekanan maksimum pada basis gigi tiruan kelompok RAPP yaitu antara (1,4-1,6 $\mathrm{MPa})$, sedangkan pada kelompok nilon termoplastik golongan ethylene propylene yaitu antara $(0,6-0,8 \quad \mathrm{MPa})$, kelompok nilon termoplastik golongan polikarbonat dan poliamida memiliki nilai yang hampir sama yaitu antara $(0,4-0,6 \mathrm{MPa})$ (Nasution dkk. 2018). Menurut penelitian Arksornnukit dkk., (2010) didapatkan bahwa anasir gigi tiruan akrilik dengan angulasi anatomis memiliki nilai transmisi tekanan yang paling tinggi dibandingkan dengan angulasi semi anatomis dan non anatomis. Nilai transmisi tekanan maksimum pada anasir gigi tiruan dengan angulasi anatomis yaitu sebesar 4,28 $\mathrm{MPa}$, angulasi semi anatomis yaitu sebesar 4,01 $\mathrm{MPa}$ dan angulasi non anatomis yaitu sebesar 1,71 $\mathrm{MPa}$. Anasir gigi tiruan porselen dengan angulasi anatomis memiliki nilai transmisi tekanan yang paling tinggi dibandingkan dengan angulasi semi anatomis dan non anatomis (anatomis 5,25 $\mathrm{MPa}>$ semi anatomis 4,98 $\mathrm{MPa}>$ non anatomis $1,57 \mathrm{MPa}$ ) (Arksornnukit dkk. 2011).

Transmisi tekanan dapat memengaruhi proses terjadinya resorpsi tulang alveolar, dimana semakin besar nilai transmisi tekanan yang dihasilkan maka semakin cepat resorpsi tulang alveolar terjadi. Matsuo dkk., mengatakan bahwa tekanan 27 hingga $68 \mathrm{~g} / \mathrm{cm}^{2}$ menyebabkan fibroblast merangsang peningkatan kalsium intraseluler yang dapat membantu remodeling tulang alveolar. Berg dkk., juga menyatakan bahwa tekanan yang melebihi 1,3 $\mathrm{kPa}$ tidak boleh didistribusikan ke jaringan pendukung gigi tiruan. Namun, nilai transmisi tekanan pada penelitian ini lebih tinggi dibandingkan dengan batas ambang maksimal. Hal tersebut dapat terjadi karena ukuran luas penampang sampel pada penelitian ini hanya $225 \mathrm{~mm}^{2}$ sedangkan ukuran luas penampang pada basis gigi tiruan penuh rahang atas adalah $2296 \mathrm{~mm}^{2}$ dan rahang bawah adalah $1225 \mathrm{~mm}^{2}$ (Arksornnukit dkk. 2011, Zarb dan Bolender 2004). Dengan demikian pada penelitian ini, area (luas penampang) untuk menyerap dan melunturkan gaya menjadi lebih kecil. Oleh karena itu, dianjurkan menggunakan luas penampang basis gigi tiruan yang lebih luas yang mencakup batas anatomis dan fisiologis. Basis gigi tiruan dengan luas penampang yang lebih besar dapat mendistribusi tekanan lebih luas, sehingga nilai transmisi tekanan yang dihasilkan dapat sesuai ataupun dibawah batas ambang normal. Transmisi tekanan pada gigi tiruan lepasan harus terdistribusi secara merata agar tidak menyebabkan terjadinya nyeri, ketidaknyamanan, peradangan dan resorpsi tulang alveolar. Serta disarankan untuk merancang gigi tiruan dengan tujuan untuk melindungi struktur rongga mulut yang tersisa dan menurunkan tekanan ke sisa alveolar (Phunthikaphadr dkk. 2009).

\section{KESIMPULAN}

1. Bahan basis gigi tiruan RAPP tetap menjadi pilihan utama dalam pemilihan bahan basis gigi tiruan. Namun, bahan basis gigi tiruan nilon termoplastik Biotone dapat digunakan sebagai alternatif dalam pemilihan bahan basis gigi tiruan pada pasien yang membutuhkan tekanan yang lebih kecil karena basis gigi tiruan Biotone memiliki nilai transmisi tekanan yang lebih rendah dibandingkan dengan basis gigi tiruan RAPP. 
2. Pemilihan bahan basis gigi tiruan yang sesuai dengan rongga mulut pasien dapat meminimalkan tekanan ke sisa alveolar dan melindungi struktur jaringan rongga mulut pasien.

\section{DAFTAR PUSTAKA}

Arksornnukit M, Phunthikaphadr T, Takahashi H. 2011. Pressure transmission and distribution under denture bases using denture teeth with different materials and cuspal angulations.

Biotone, Denken-Highdental Co., Ltd., Kyoto, Japan. http://www.kdf.co.jp/english/materials/ m05/m05 4 . (15 Juni 2019).

Callister WD, Rethwisch DG. 2010 Material science and engineering. $8^{\text {th }}$ ed. USA: Wiley.

Cunningham JL. 1993. Bond strength of denture teeth to acrylic bases.

Fueki K, Ohkubo C, Yatabe M, Arakawa I, Arita M, Ino S, dkk. 2014. Clinical application of removable partial dentures using thermoplastic resin Part I: Definition and indication of non-metal clasp dentures.

Hamanaka I, Misa I, Lippo VJL, Pekka KV, Yutaka T. 2016. Wear resistance of injection-molded thermoplastic denture base resins.

Kohli S, Bhatia S. 2013. Polyamides in dentistry.

Nasution H, Kamonkhantikul K, Arksornnukit M, Takahashi H. 2018. Pressure transmission area and maximum pressure transmission of different thermoplastic resin denture base materials under impact load.

Phunthikaphadr T, Takahashi H, Arksornnukit M. 2009. Pressure transmission and distribution under impact load using artificial denture teeth made of different materials.

Saavedra G, Valandro LF, Leite FP, Amaral L, Ozcan M, Bottino MA, et al. 2007.
Bond strength of acrylic teeth to denture base resin after various surface conditioning methods before and after thermocycling.

Sari NMGAW, Fardaniah S, Masulili C. 2017. Color changing in denture base polyamide 12 and polyamide microcrystalline after polishing in laboratory and dental clinic.

Sundari I, Sofya PA, Hanifa M. 2016. Studi kekuatan fleksural antara resin akrilik heat cured dan termoplastik nilon setelah direndam dalam minuman kopi uleekareng (Coffea robusta).

Tenripada N, Wahyuningtyas E, Sugiatno E. 2014. Pengaruh derajat keasaman saliva terhadap modulus elastisitas termoplastik nilon dan polikarbonat sebagai bahan basis gigi tiruan.

Vivek R, Soni R. 2015. Denture base materials: Some relevant properties and their determination.

Vivek R. 2016. Polyamides as a denture base material - A review.

Zarb GA, Bolender CL. 2004. Prosthodontic treatment for edentulous patients; complete dentures and implant - supported prostheses. $12^{\text {th }}$ ed. Philadelphia: Mosby. 